\title{
Induction of Tolerance by Oral Administration of Beta-Tubulin in an Animal Model of Autoimmune Inner Ear Disease
}

\author{
Qing Cai ${ }^{\mathrm{a}, \mathrm{c}}$ Xiaoping Du ${ }^{\mathrm{b}}$ Bin $\mathrm{Zhou}^{\mathrm{a}}$ Chun Cai ${ }^{\mathrm{a}}$ \\ Mohammad Habiby Kermany ${ }^{a}$ Taijune Yoo ${ }^{a}$ \\ a Department of Medicine, Department of Molecular Sciences, Department of Otolaryngology, Neuroscience \\ Institute, and ${ }^{b}$ Department of Anatomy and Neurobiology, University of Tennessee Health Science Center, \\ Memphis, Tenn., USA; ' Department of Otolaryngology, Renmin Hospital of Wuhan University, Hubei, PR China
}

\section{Key Words}

Oral tolerance $\cdot \beta$-Tubulin $\cdot$ Autoimmune inner ear disease, mice

\begin{abstract}
Induction of peripheral tolerance by oral administration of low-dose $\beta$-tubulin antigen may be an effective, antigenspecific method to suppress experimental autoimmune hearing loss. Five groups of mice were fed with phosphatebuffered saline (PBS), ovalbumin (OVA), 20, 30 or $200 \mu \mathrm{g}$ of $\beta$-tubulin, respectively. All mice were then immunized by $\beta$ tubulin. Hearing thresholds were measured before and after immunization. Inner ear histology and cytokine profile were examined. Mice fed with 20 or $30 \mu \mathrm{g}$ of $\beta$-tubulin showed less hearing loss and less inner ear damage compared to the groups treated with PBS, OVA or $200 \mu \mathrm{g}$ of $\beta$-tubulin. Interferon-gamma (IFN- $\gamma$ ) was decreased while interleukin-4 (IL-4), IL-5, IL-13 and TGF- $\beta$ were increased in both sera and in cell culture supernatants of the mice fed with 20 or $30 \mu \mathrm{g}$ of $\beta$-tubulin. However, no cytokine profile change was found in the group treated with $200 \mu \mathrm{g}$ of tubulin. These results suggest that a low dose of $\beta$-tubulin is active orally in an an-
\end{abstract}

tigen-specific fashion and capable of inhibiting the autoimmune reactions in the inner ear by suppressing Th1 (IFN- $\gamma$ ) and increasing Th2 and Th3 (IL-4, IL-5, IL-13 and TGF- $\beta$ ) cytokines. Oral antigen tolerance may be used to treat autoimmune inner ear disease.

Copyright $\odot 2009$ S. Karger AG, Basel

\section{Introduction}

Several studies have indicated that the inner ear is not a privileged site for initial antigen stimulation [1-3]. It is proposed that the immune component cells initially activated in the periphery migrate into the inner ear and subsequently develop an immune response to the antigen locally. The weight of recent evidence strongly implicates immunological and/or chronic inflammatory processes as contributing to the pathogenesis of autoimmune inner ear disease. Consistent with the autoimmune mechanism, various pathological changes have been found in several animal models of autoimmune inner ear disease, including degeneration of the spiral ganglion, atrophy of Corti's organ and the endolymphatic duct epithelium,

\section{KARGER}

Fax +4161306 1234 E-Mail karger@karger.ch www.karger.com
(C) 2009 S. Karger AG, Basel

0301-1569/09/0713-0135\$26.00/0

Accessible online at:

www.karger.com/orl
Taijune Yoo, MD, $\mathrm{PhD}$

920 Madison

Room 923

Memphis, TN 38163 (USA)

Tel. +1 901448 5397, Fax +1 901347 8191, E-Mail tyoo@utmem.edu 
vasculitis in the cochlea, otospongiotic changes of the bone of the external meatus and otic capsule, as well as hearing loss and vestibular dysfunction $[4,5]$.

In autoimmune inner ear diseases, disrupted normal mechanisms of tolerance for self-proteins result in a destructive immune response against the individual's own tissue proteins. However, the specific antigen that elicits the autoimmune reactions in the inner ear is still unknown [4]. Recently, we have isolated a 55-kDa protein from the guinea pig inner ear, which has amino acid sequences similar to $\beta$-tubulin. We have also cloned the $\beta$-tubulin gene by using guinea pig inner ear cDNA library screening [6]. An immunohistological study using a monoclonal antitubulin antibody found positive staining in Corti's organ, spiral limb, cochlear nerve fibers and neurons in the spiral ganglions of guinea pigs, and tubulin immunization changed the immune staining pattern. However, no inner ear hydrops was found in those tubulin-immunized animals [7]. Furthermore, the antibody against $\beta$-tubulin was found in sera of about $64 \%$ of patients suffering from autoimmune inner ear diseases [6-9].

Oral tolerance is a long recognized method of inducing tolerance. It refers to the observation that if one is fed with a protein and then immunized with the same protein, a state of systemic hyporesponsiveness to the protein exists. Oral administration of an antigen is often characterized by marked suppression of the cell-mediated immune response to immunization with the same antigen. In recent years, investigators have begun to apply oral tolerance as a method to manipulate injurious immune responses, primarily in the area of autoimmune diseases. Although it was described by Wells in 1911 and Chase in 1946 , oral tolerance has recently been proposed as an important mechanism to suppress the immune process in experimental models of autoimmune diseases [10].

This method has been successfully applied in autoimmune diseases such as experimental allergic encephalomyelitis, collagen-induced arthritis and type I diabetes mellitus. Oral tolerance probably induces interleukin-4 (IL-4), interleukin-6 (IL-6) and transforming growth factor beta (TGF- $\beta$ ) and simultaneously suppresses or inhibits the Thla (T helper cell) cellular responses in these autoimmune diseases. Although the detailed immune mechanism in oral tolerance is not clear, both active suppression and clonal anergy or clonal deletion have been suggested [10-12]. While low-dose antigen treatment induces an active suppression mechanism, high-dose antigen treatment selects clonal anergy [10-12].

Our purpose was to evaluate T cell responses to $\beta$-tubulin after oral administration of $\beta$-tubulin in an auto- immune hearing loss mouse model. We hypothesized that oral administration of $\beta$-tubulin to tubulin-immunized mice can induce suppression of $\beta$-tubulin T cells, which recognize specific $\beta$-tubulin peptide complexes. This suppression would produce either an altered profile of lymphokines, the majority of which are suppressive types and are capable of downregulating inflammation and the autoimmune process, or allergic and refractory to subsequent stimulation.

\section{Materials and Methods}

\section{Animals}

Female C57BL/6 4 weeks old mice were purchased from the Jackson Laboratory (Bar Harbor, Me., USA). Female mice were used in the present study because female autoimmune mice have greater hearing loss than males [13]. They were housed in the animal room of the Veterans Administration Medical Center, Memphis. The animal procedures used in this study were approved by the Institutional Animal Care and Use Committees at the University of Tennessee Health Science Center, Memphis.

\section{$\beta$-Tubulin Protein Expression}

The $\beta$-tubulin gene was expressed as a glutathione-S-transferase fusion protein by subcloning into the prokaryotic expression vector pGEX-5X-3. Briefly, the open reading frame starting with the first ATG was PCR-amplified using primers flanked with EcoRI and NotI sites (forward: CAC GTT TGG TGG TGG CGA CCA; reverse: AGA GGT TTT CAC CGT CAT CAC), respectively.

\section{Oral Administration of $\beta$-Tubulin}

Thirty mice were randomly divided into 5 groups. Two groups were used as controls: one group of mice was fed with $0.2 \mathrm{ml}$ of phosphate-buffered saline (PBS)/day; the second group was fed with $1 \mathrm{mg}$ of ovalbumin (OVA)/day (Sigma Chemical Co., St. Louis, Mo., USA) in $0.2 \mathrm{ml}$ PBS. The other 3 groups were fed with 20, 30 or $200 \mu \mathrm{g} /$ day of $\beta$-tubulin, respectively. All mice were fed by gastric intubation with an 18-gauge stainless-steel feeding tube (Thomas Scientific, Swedesboro, N.J., USA). Animals were fed once a day for 5 days and immunized 2 days after the last feeding.

\section{Immunization}

All mice were immunized with $100 \mu$ g of $\beta$-tubulin emulsified with an equal volume of complete Freund's adjuvant on the lateral back. The immunization was boosted with $100 \mu \mathrm{g}$ of $\beta$-tubulin emulsified with an equal volume of incomplete Freund's adjuvant 2 and 4 weeks later.

Auditory-Evoked Brain Stem Response Tests

Auditory function was evaluated by performing auditoryevoked brainstem response (ABR) tests. Mice were intraperitoneally anesthetized with Avertin (tribromoethanol, $500 \mathrm{mg} / \mathrm{kg}$ body weight). Body temperature was kept stable with a heating pad throughout the experiment at $37^{\circ} \mathrm{C}$. Response signals were recorded with subcutaneous needle electrodes inserted at the vertex 
in the midline of the scalp between the external auditory canal (active), left ear postauricular bulla region (reference) and the back close to the tail (ground). Click and tone pips of 8, 16 and 32 $\mathrm{kHz}$ were generated using a Tucker Davis Technologies Inc. (Gainesville, Fla., USA) workstation (System II) running Siggen 32 software (Tucker Davis Technologies). Stimuli were delivered to the left external auditory meatus through a $2-\mathrm{mm}$ diameter plastic tube connected to a high-frequency transducer in a controlled acoustic chamber (Industrial Acoustics Company, Bronx, N.Y., USA). The output was fed to an amplifier (HS4 Bioamp Headstage, Tucker Davis Technologies). A maximum sound pressure level (SPL) was stimulated in clicks of $85 \mathrm{~dB}$ and in tone pips of $90 \mathrm{~dB}$. The stimulus duration was $10 \mathrm{~ms}$ with $1-\mathrm{ms}$ rise/fall time at a repetition rate of $21 / \mathrm{s}$. The band pass filters were set at $300 \mathrm{~Hz}$ to $3 \mathrm{kHz}$. The evoked potentials were amplified 100,000 times and averaged from a total of 500 evoked responses for the first $10-\mathrm{ms}$ period following stimulation. Auditory thresholds were determined by increasing the sound intensities of the click and tone pips for each stimulus from 15 to $85 \mathrm{~dB}$ and from 25 to $90 \mathrm{~dB}$, respectively, first at $10-\mathrm{dB}$ steps and finally at $5-\mathrm{dB}$ steps, until reaching the lowest sound intensity at which reproducible waves could be recognized in the response. Thresholds were verified at least twice, and the mean thresholds were calculated. If ABRs could not be obtained with the maximum SPL of $90 \mathrm{~dB}$ in tone pips, a nominal threshold of $95 \mathrm{~dB}$ was assigned.

\section{Cell Culture, Proliferation and ELISA for Cytokines}

Mice were deeply anesthetized at 7 weeks after the immunization, and spleen cells were harvested. For proliferation assays and cytokine analyses, lymphocytes were cultured in 96-well plates at $5 \times 10^{6}$ or $10 \times 10^{6}$ cells $/ \mathrm{ml}$, respectively, in an X-Vivo 20 incubator (Biowhittaker, Walkersville, Md., USA). For proliferation assays, cells were pulsed with $\left[{ }^{3} \mathrm{H}\right]$ thymidine, $72 \mathrm{~h}$ later; radioactivity was measured after a 16-hour incubation. Culture supernatants were collected at $24 \mathrm{~h}$ for IL-2 and IL-4, at $40 \mathrm{~h}$ for IL-13, IL-10 and interferon-gamma (IFN- $\gamma$ ), and at $72 \mathrm{~h}$ for TGF- $\beta$. Sera collected from each mouse at 3, 5 and 7 weeks after primary immunization was used for cytokine analysis by ELISA (R\&D Systems, Minneapolis, Minn., USA).

\section{Histopathological Study}

The anesthetized mice were intracardially perfused with $0.1 \mathrm{M}$ PBS followed by $4 \%$ paraformaldehyde in $0.1 \mathrm{M}$ PBS ( $\mathrm{pH}$ 7.4). The cochlea was removed from the temporal bone and postfixed in the same fixative overnight. The fixed cochlea was decalcified with $10 \%$ ethylenediaminetetraacetic acid in $0.1 \mathrm{M}$ PBS for 3-4 weeks with a change of solution every week. The decalcified cochlea was washed with 0.1 M PBS 3 times, then dehydrated in graded alcohols and embedded in paraffin. The paraffin-embedded cochleas were sectioned at $6 \mu \mathrm{m}$ thickness with a microtome. Sections were mounted on slides and deparaffinized with xylene and graded ethanol; then they were stained with hematoxylin and eosin. All sections were examined with a light microscope (Carl Zeiss Axioskop 2 plus HAL 100 with final enlargement $\times 400)$. Digital images were obtained using a camera (Leica) linked to a Windows computer.

Statistical Analysis

ABR thresholds and cytokine concentrations were analyzed by ANOVA.

$\beta$-Tubulin in an Animal Model of Autoimmune Inner Ear Disease

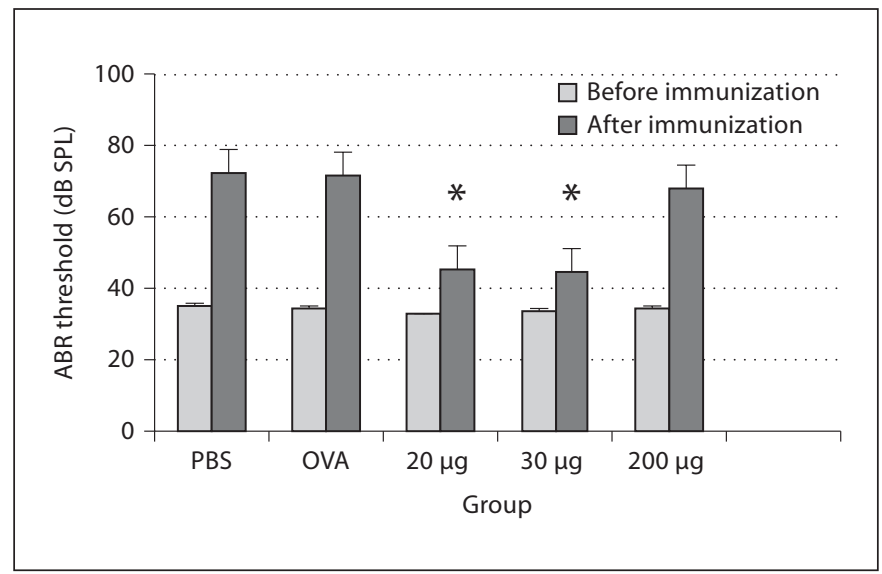

Fig. 1. Results of the ABR test: hearing threshold changes before and after $\beta$-tubulin immunization. Significant threshold shifts are detected in the groups administered PBS, OVA and $200 \mu \mathrm{g}$ of tubulin. However, fewer threshold shifts are found in the groups treated with 20 and $30 \mu \mathrm{g}$ of tubulin $\left({ }^{*} \mathrm{p}<0.05\right)$.

\section{Results}

\section{Less Hearing Loss Was Found in the Groups with \\ Low-Dose $\beta$-Tubulin Oral Administration}

The groups fed with PBS, OVA and $200 \mu \mathrm{g} \beta$-tubulin were found to have severe hearing loss with $35.5,35.5$ and $33.5 \mathrm{~dB}$ SPL threshold shifts, respectively. No significant difference was found between the group fed with $200 \mu \mathrm{g}$ $\beta$-tubulin and any control group ( $p>0.05)$. However, the threshold shifts were only approximately $10 \mathrm{~dB}$ SPL in the mice fed with 20 and $30 \mu \mathrm{g} \beta$-tubulin. The differences in the threshold shifts between the mice fed with 20 or $30 \mu \mathrm{g} \beta$-tubulin and the control groups are statistically significant $(\mathrm{p}<0.05)$, suggesting an effective protection to the inner ears by the low-dose oral administration of tubulin (fig. 1).

\section{Changes in Cytokine Levels after $\beta$-Tubulin Oral \\ Administration and Immunization}

Three weeks after the primary immunization, the profile of the sera's cytokine production showed that levels of IFN- $\gamma$ and IL-10 decreased, but levels of IL-4, IL-5, IL-13 and TGF- $\beta$ increased in the mice fed with 20 and $30 \mu \mathrm{g}$ of $\beta$-tubulin (fig. 2). Five weeks after the primary immunization, the profile of the sera's cytokine production showed that the level of IFN- $\gamma$ decreased, but levels of IL-4, IL-5 and IL-10 increased in the mice fed with 20 and $30 \mu \mathrm{g}$ of $\beta$-tubulin (fig. 3). Seven weeks after the primary immunization, the cytokine profile of the lympho- 
Fig. 2. Profile of serum cytokine production at 3 weeks after the primary immunization. Levels of IFN- $\gamma$ and IL-10 decreased while levels of IL-4, IL-5, IL-13 and TGF- $\beta$ increased in the mice fed with 20 and $30 \mu \mathrm{g}$ of $\beta$-tubulin. ${ }^{*} \mathrm{p}<0.05$. No significant changes of the cytokine levels are found in the group fed with $200 \mu \mathrm{g}$ of $\beta$-tubulin.

Fig. 3. Profile of serum cytokine production at 5 weeks after the primary immunization. The level of IFN- $\gamma$ decreased while levels of IL-4, IL-5 and IL-10 increased in the mice fed with 20 and $30 \mu \mathrm{g}$ of $\beta$-tubulin. ${ }^{*} \mathrm{p}<0.05$. No significant changes of the cytokine levels are found in the group treated with $200 \mu \mathrm{g}$ of $\beta$-tubulin.
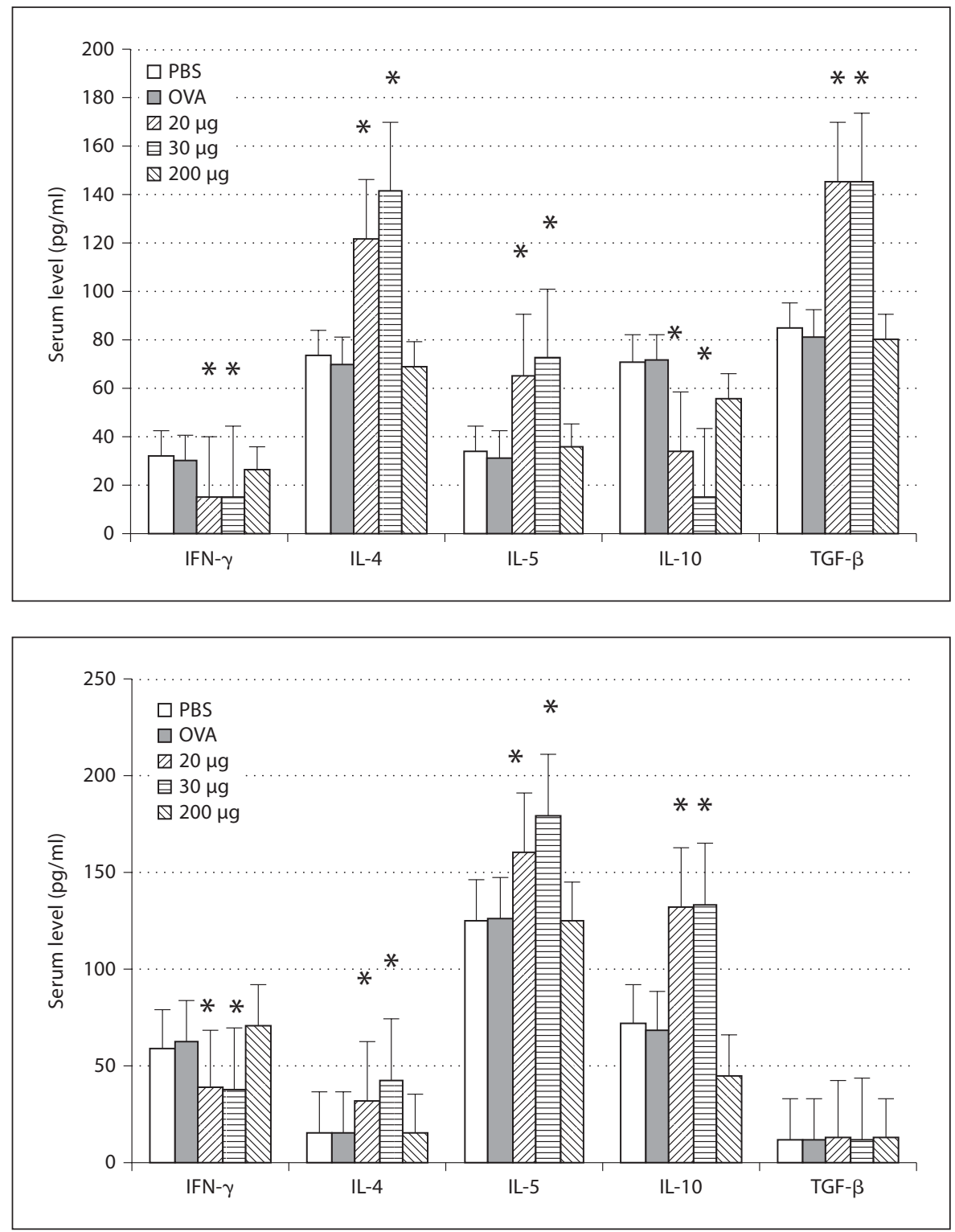

cyte culture supernatant showed that the level of IFN- $\gamma$ decreased, but levels of IL-4, IL-13, IL-10 and TGF- $\beta$ increased in the mice fed with 20 and $30 \mu \mathrm{g}$ of $\beta$-tubulin (fig. 4).

These results demonstrate that orally administered $\beta$ tubulin in $\beta$-tubulin-immunized animals suppressed Th1 (IFN- $\gamma$ ) and increased Th2 and Th3 (IL-4, IL-5, IL13 and TGF- $\beta$ ). However, the IL-10 level decreased 3 weeks after immunization, but significantly increased at 5 and 7 weeks, suggesting a rebounding effect after an initial inhibition.
However, it is still unclear why oral administration of $200 \mu \mathrm{g}$ tubulin did not change any cytokine's level at all 3 time points tested in the present study. Furthermore, levels of cytokines, for example the value of IL-4, were fluctuating at 3 time points. This fluctuation is thought to be caused by the amount of the antibody coated in the ELISA. However, this fluctuation does not affect the analysis since all samples from a time point were tested at the same time. 
Fig. 4. Profile of serum cytokine production at 7 weeks after the primary immunization. The level of IFN- $\gamma$ decreased while levels of IL-4, IL-13, IL-10 and TGF- $\beta$ increased in the mice fed with 20 and $30 \mu \mathrm{g}$ of $\beta$-tubulin. ${ }^{*} \mathrm{p}<0.05$. No significant changes of the cytokine levels are found in the group administered $200 \mu \mathrm{g}$ of $\beta$-tubulin.

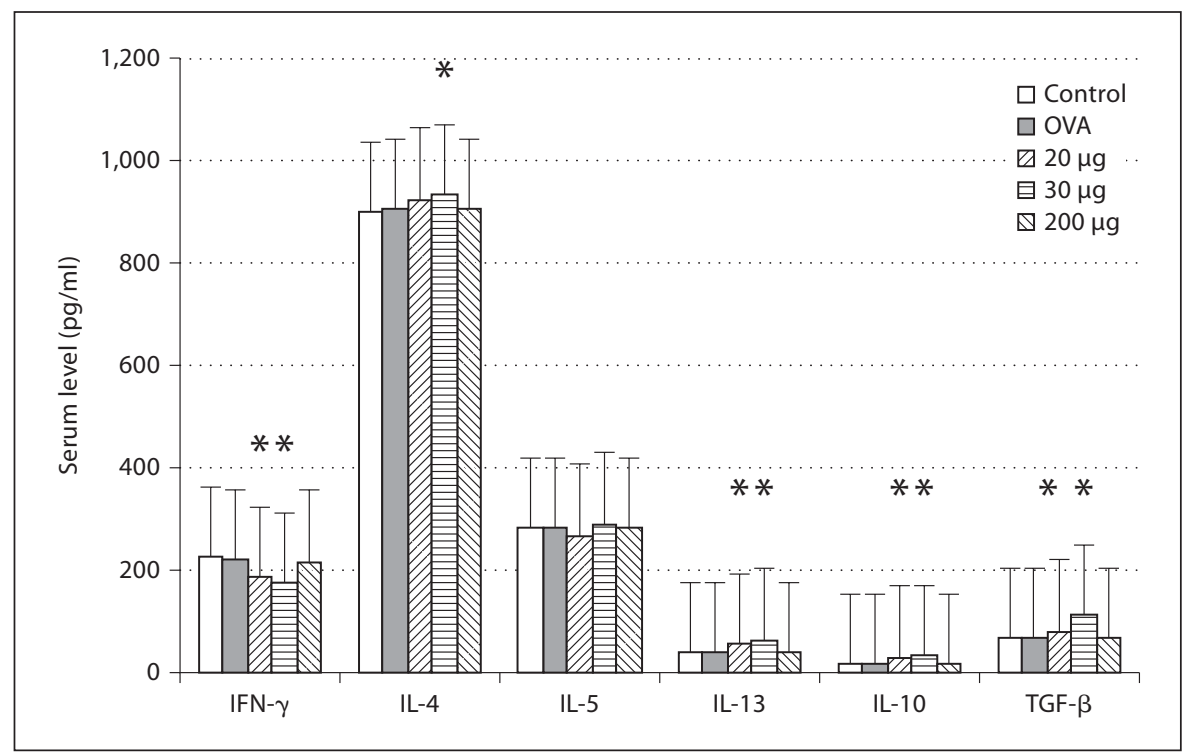

\section{Less Inner Ear Damage Was Found in Low-Dose}

Beta-Tubulin Administration Groups

Histopathology of the cochleas was examined 7 weeks after primary immunization. The organ of Corti was missing at the basal turns of the cochleas in the groups treated with PBS, OVA and $200 \mu \mathrm{g} \beta$-tubulin (arrows in fig. $5 a-c)$. Most of the neurons in the spiral ganglion are missing in the PBS and OVA groups (arrowheads in fig. 5a and $b$ ). However, most of the neurons in the spiral ganglion are preserved in the group fed with $200 \mu \mathrm{g} \beta$-tubulin (arrowhead in fig. 5c). In contrast, the organ of Corti (open arrows in fig. $5 \mathrm{~d}$ and e) and neuron in the spiral ganglion (open arrowheads in fig. $5 \mathrm{~d}$ and e) are preserved in the groups fed with 20 and $30 \mu \mathrm{g}$ of $\beta$-tubulin. The results demonstrate a protection by low-dose oral administration of tubulin to the cochlea and the spiral ganglions.

\section{Discussion}

Peripheral tolerance by oral antigen administration has been demonstrated in several autoimmune animal models, including proteolipid protein-induced experimental allergic encephalomyelitis, the diabetic mouse and adjuvant arthritis. In all 3 of these models, autoimmunity to the tolerance does not appear to initiate but suppress the disease when the tolerance is given orally [14-19]. This phenomenon is also found in an experimental model of asthma [20]. In the present study, low-dose
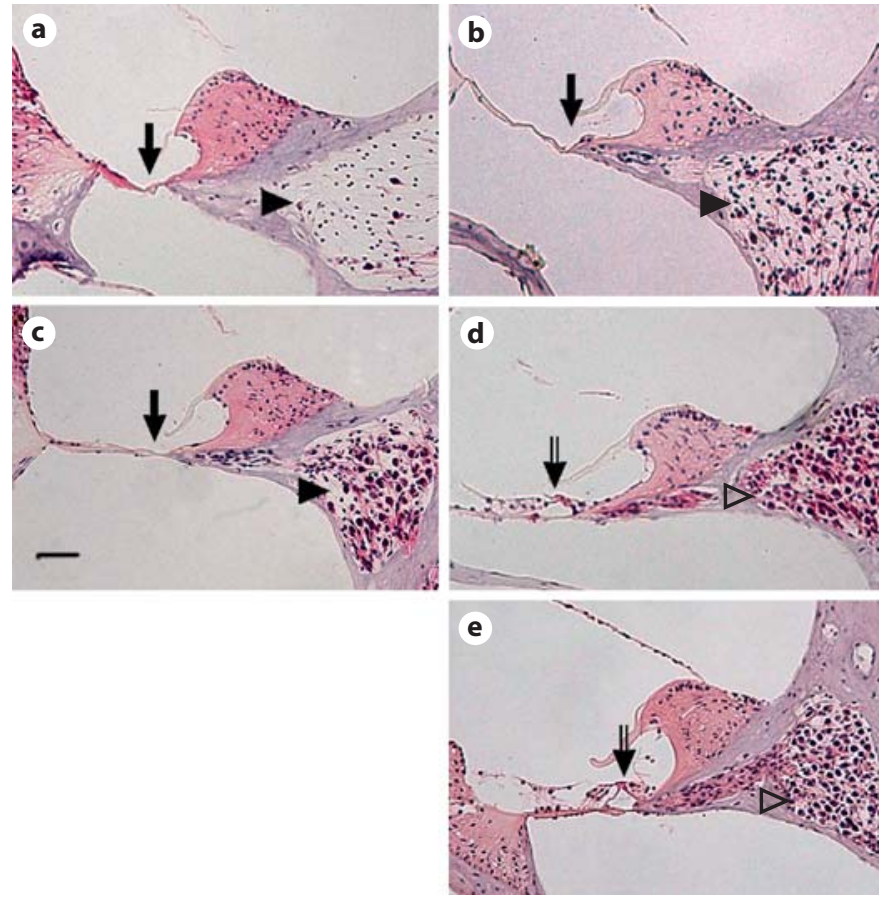

Fig. 5. Illustration of hematoxylin-eosin staining in the cochlear basal turn. The inner ear histology illustrates that the cochleas of the PBS (a), OVA (b) and 200- $\mu$ g groups (c) had the organ of Corti missing (arrows) and neuron loss in the spiral ganglion (arrowheads). However, hair cells in the organ of Corti (open arrows in $\mathbf{d}, \mathbf{e}$ ) and neurons in the spiral ganglion (open arrowheads in $\mathbf{d}, \mathbf{e}$ ) are preserved in groups orally fed with 20 and $30 \mu \mathrm{g}$ of $\beta$-tubulin (d, e). Scale bar $=50 \mu \mathrm{m}$. 
oral administration of tubulin ( 20 or $30 \mu \mathrm{g})$ is effective in preventing inner ear damage and hearing loss, which are associated with autoimmune inner ear diseases. These results have demonstrated that oral tolerance may be used to treat autoimmune inner ear diseases.

Orally administered antigens can induce tolerance by a number of mechanisms including anergy, deletion and the induction of regulatory cells that secrete IL-4, IL-10 and TGF- $\beta$ [21-23]. However, the mechanisms of immune tolerance are associated with the dose of antigen fed, whereas higher antigen doses induce anergy or deletion.

Upregulation of IL-4, IL-5, IL-13 and TGF- $\beta$ and downregulation of IFN- $\gamma$ have been detected throughout the experimental period (up to 7 weeks) after the administration of the low dose of tubulin. Downregulation of IFN- $\gamma$ is also found in oral tolerance in the T cell receptor transgenic mice $[24,25]$ and in murine gut-associated lymphoid tissue [26]. Low antigen doses also favor the induction of Th2-type regulatory T cells that secrete IL-4 and IL-13 and Th3-type regulatory cells that secrete TGF$\beta$ and IL-10 [21-23, 27, 28], which is supported by our observation. Furthermore, studies using knockout animals have demonstrated that low doses of antigen induce active suppression, probably via induction of CD4-CD8+ suppressor $\mathrm{T}$ cells or mediated by $\mathrm{CD} 4+\mathrm{CD} 8+\mathrm{T}$ cells [29]. In the present study, IL-10 is not upregulated until 5 weeks after the primary immunization, suggesting a non-antigen-specific downregulation of this cytokine [30], while secretion of TGF- $\beta$ is antigen specific [24]. Furthermore, secretion of TGF- $\beta$ is generally dissociated with IL-10/IL-4 [31].

High-dose-induced tolerance has been found in various animal models. Animals fed high doses of antigen secrete more IL- 4 and less TGF- $\beta$ [32-35]. High doses of orally administered antigen resulted in anergy/deletion of specific $\mathrm{T}$ cells in the gut and in systemic antigen presentation after antigen has passed through the gut. Presentation of high doses of antigen would induce unresponsiveness of $\mathrm{T}$ cell function, primarily via anergy/deletion $[32,33]$. In the present study, however, no tolerance has been found in the administration of high doses of tubulin, which is demonstrated by more hearing loss and severer inner ear damage in the mice treated with the high dose of tubulin. Consistent with this observation, no significant cytokine profile changes were observed in the high-dose $(200 \mu \mathrm{g})$ administration of tubulin. This phenomenon may be related to the dose of tubulin used in the present study, which is about 10 times higher than the low dose $(20-30 \mu \mathrm{g})$. A relatively lower dose of tubulin, for example $100 \mu \mathrm{g}$, has to be tested in future.
Th1 cytokines (IL-2 and IFN- $\gamma$ ) activate macrophages, NK cells and cell-mediated immunity which may play a crucial role in immune-mediated inner ear diseases [36]. Expression of IFN- $\gamma$ following secondary immune reaction in the endolymphatic sac can then upregulate intercellular adhesion molecule 1 expression and induce cell infiltration [37]; then it may cause inflammatory cell damage in the inner ear. On the other hand, Th2 cytokines favor isotype switching in the humoral immune response and depress macrophage activation and cell-mediated immunity, which antagonize the Th1 cytokines. In the present study, oral low-dose tubulin administration inhibits Th1 cytokines and upregulates Th2 cytokines. Rebalanced Th1 and Th 2 cytokines in the inner ear do not favor inflammatory cell infiltration and further protect the hair cells and prevent hearing loss.

In summary, our present study has demonstrated that $\beta$-tubulin is orally active in an antigen-specific fashion and capable of inhibiting the autoimmune reactions in the inner ear by suppressing Th1 (IFN- $\gamma$ ) and increasing Th2 and Th3 (IL-4, IL-5, IL-13 and TGF- $\beta$ ) cytokines. Oral antigen tolerance may be used to treat autoimmune inner ear disease in future.

\section{Acknowledgments}

We would like to thank Dr. David L. Armbruster (PhD, Scientific Publication Consultations, Health Science Center, University of Tennessee) for reading and commenting on the manuscript. This work was supported by National Institutes of Health grant R01-R073375065.

References

1 Satoh H, Firestein GS, Billings PB, Harris JP, Keithley EM: Tumor necrosis factor- $\alpha$, an initiator, and etanercept, an inhibitor of cochlear inflammation. Laryngoscope 2002; 112:1627-1634.

2 Harris JP, Ryan AF: Fundamental immune mechanisms of the brain and inner ear. Otolaryngol Head Neck Surg 1995;112:639-653.

-3 Ryan AF, Keithley EM, Harris JP: Autoimmune inner ear disorders. Curr Opin Neurol 2001; 14:35-40.

-4 Yoo TJ, Stuart JM, Kang AH, Townes AS, Tomoda K, Dixit S: Type II collagen autoimmunity in otosclerosis and Ménière's disease. Science 1982;217:1153-1155.

5 Suzuki M, Yazawa Y, Yoo TJ, Cheng KC, Krug MS, Bernstein J: Antibodies against inner ear proteins in the sera of patients with inner ear disease. ORL 1997;59:10-17. 
6 Yoo TJ, Tanaka H, Kwon SS, Krug M, Yazawa Y, Suzuki M, Kitajima K: $\beta$-Tubulin as an autoantigen for autoimmune inner ear disease; in Sterkers O, Ferrary E, Dauman R, Sauvage JP, Tran Bahuy P (eds): Ménière's Disease. The Hague, Kugler, 2000, pp 529-535.

7 Du X, Yoo TJ, Mora R: Distribution of betatubulin in the guinea pig inner ear. ORL 2003;65:7-16

$\checkmark 8$ Yoo TJ, Shea J Jr, Ge X, Kwon SS, Yazawa Y, Sener O, Mora F, Mora R, Mora M, Barbieri M, Du X: Presence of autoantibodies in the sera of Ménière's disease. Ann Otol Rhinol Laryngol 2001;110:425-429.

9 Suzuki M, Krug MS, Cheng KC, Yazawa Y, Bernstein J, Yoo TJ: Antibodies against inner ear proteins in the sera of patients with inner ear disease. ORL J Otorhinolaryngol Relat Spec 1997;59:10-17.

-10 Teitelbaum D, Arnon R, Sela M: Immunomodulation of experimental autoimmune encephalomyelitis by oral administration of copolymer 1. Proc Natl Acad Sci USA 1999; 96:3842-3848.

-11 Maron R, Slavin AJ, Hoffmann E, Komagata Y: Oral tolerance to copolymer 1 in myelin basic protein (MBP) TCR transgenic mice: cross-reactivity with MBP-specific TCR and differential induction of anti-inflammatory cytokines. Int Immunol 2002;14:131-138.

12 Benson JM, Stuckman SS, Cox KL: Oral administration of myelin basic protein is superior to myelin in suppressing established relapsing experimental autoimmune encephalomyelitis. J Immunol 1999;162:62476254.

-13 Trune DR, Kempton JB: Female MRL.MpJFaslpr autoimmune mice have greater hearing loss than males. Hear Res 2002;167:170174.

-14 Gonnella PA, Kodali D, Weiner HL: Induction of low dose oral tolerance in monocyte chemoattractant protein-1- and CCR2-deficient mice. J Immunol 2003;170:2316-2322.

-15 Zhang ZJ, Davidson L, Eisenbarth G, Weiner HL: Suppression of diabetes in nonobese diabetic mice by oral administration of porcine insulin. Proc Natl Acad Sci USA 1991;88: 10252-10258

$\checkmark 16$ Kim N, Cheng KC, Kwon SS, Mora R, Barbieri M, Yoo TJ: Oral administration of collagen conjugated with cholera toxin induces tolerance to type II collagen and suppresses chondritis in an animal model of autoimmune ear disease. Ann Otol Rhinol Laryngol 2001;110:646-654.
17 Nagler-Anderson C, Bober LA, Robinson ME, Siskind GW, Thorbecke GJ: Suppression of type II collagen-induced arthritis by intragastric administration of soluble type II collagen. Proc Natl Acad Sci USA 1986;83: 7443-7446.

18 Thompson HS, Staines NA: Gastric administration of type II collagen delays the onset and severity of collagen-induced arthritis in rats. Clin Exp Immunol 1986;64:581-586.

19 Chen Y, Inobe J, Weiner HL: Induction of oral tolerance to myelin basic protein in CD8-depleted mice: both CD4+ and CD8+ cells mediate active suppression. J Immunol 1995;155:910-916.

20 Nagatani K, Dohi M, To Y, Tanaka R, Okunishi K, Nakagome K, Sagawa K, Tanno Y, Komagata Y, Yamamoto K: Splenic dendritic cells induced by oral antigen administration are important for the transfer of oral tolerance in an experimental model of asthma. J Immunol 2006;176:1481-1489.

21 Ke Y, Kapp JA: Oral antigen inhibits priming of CD8+ CTL, CD4+ T cells, and antibody responses while activating CD8+ suppressor T cells. J Immunol 1996;156:916-921.

22 Chen Y, Inobe J, Weiner HL: Induction of oral tolerance to myelin basic protein in CD8-depleted mice: both CD4+ and CD8+ cells mediate active suppression. J Immunol 1995;155:910-916.

23 Miller A, Lider O, Roberts AB, Sporn MB, Weiner HL: Suppressor T cells generated by oral tolerization to myelin basic protein suppress both in vitro and in vivo immune responses by the release of TGF- $\beta$ following antigen specific triggering. Proc Natl Acad Sci USA 1992;89:421-425.

24 Chen Y, Inobe J, Weiner HL: Inductive events in oral tolerance in the TCR transgenic adoptive transfer model. Cell Immunol 1997;178: 62-68.

25 Marth T, Strober W, Kelsall BL: High dose oral tolerance in ovalbumin TCR-transgenic mice: systemic neutralization of IL-12 augments TGF-beta secretion and T cell apoptosis. J Immunol 1996;157:2348-2357.
26 Spiekermann GM, Nagler-Anderson C: Oral administration of the bacterial superantigen staphylococcal enterotoxin B induces activation and cytokine production by $\mathrm{T}$ cells in murine gut-associated lymphoid tissue. J Immunol 1998;161:5825-5831.

27 Chen Y, Kuchroo VK, Inobe JI, Hafler DA, Weiner HL: Regulatory T cell clones induced by oral tolerance: suppression of autoimmune encephalomyelitis. Science 1994;265: 1237-1240.

28 Melamed D, Friedman A: Direct evidence for anergy in T lymphocytes tolerized by oral administration of ovalbumin. Eur J Immunol 1993;23:935-942.

29 Smith KM, Eaton AD, Finlayson LM, Garside P: Oral tolerance. Am J Respir Crit Care Med 2000;162:175-178.

30 Faria AM, Weiner HL: Oral tolerance: mechanism and therapeutic applications. Adv Immunol 1999;73:153-264.

-31 Weiner HL: Induction and mechanism of action of transforming growth factor- $\beta$ secreting Th3 regulatory cells. Immunol Rev 2001; 182:207-214

$>32$ Whitacre CC, Gienapp IE, Orosz CG, Bitar DM: Oral tolerance in experimental autoimmune encephalomyelitis. III. Evidence for clonal anergy. J Immunol 1991;147:21552163.

$>33$ Friedman A, Weiner HL: Induction of anergy or active suppression following oral tolerance is determined by antigen dosage. Proc Natl Acad Sci USA 1994;91:6688-6692.

>34 Miller A, Lider O, Roberts AB, Sporn MB, Weiner HL: Suppressor T cells generated by oral tolerization to myelin basic protein suppress both in vivo and in vitro immune response by the release of transforming growth factor beta after antigen-specific triggering. Proc Natl Acad Sci USA 1992;89:421-425.

$>35$ Chen Y, Inobe JI, Marks R, Gonnella P, Kuchroo VK, Weiner HL: Peripheral deletion of antigen-reactive T cells following oral tolerance. Nature 1995;376:177-180.

-36 Pawankar R, Tomiyama S, Ikezono T, Nonaka M, Jinnouchi K, Yagi T: Interferon-gamma expression in the inner ear of rats following secondary immune reaction in the endolymphatic sac. Acta Otolaryngol Suppl 2004;553:6-12.

-37 Tomiyama S: Th1: mediator lymphocytes in experimental autoimmune labyrinthitis. Acta Otolaryngol 2001;121:673-678. 